\title{
The use of liquid vermicompost microcapsules as a complement in food for juvenile white shrimp
}

\begin{abstract}
Organic acids, worms, and other high protein substances, containing most of the essential amino acids, have been proven to bean excellent food additive for fish and in aquaculture, especially for shrimp culture. The worm Eisenia foetida and vermicompost sub products have been used as a protein source because of their high protein content, between 50 and $67 \%$; they have been included in experimental aquatic feeds, but their use is less known in shrimp culture and has not been tested as a food complement for shrimps. In this study, we added microcapsules with liquid vermicompost as a natural immune enhancer to stimulate disease resistance in shrimp, but they were used also as a complement in shrimp food to observe their survival and growth. Ground commercial shrimp food (CSF) with $40 \%$ protein was added to each of eight treatments as follows: $\mathrm{A} 2: \mathrm{CSF}+2 \%$ of cow manure microencapsulated liquid vermicompost (CMMLV); $\mathrm{A} 3: \mathrm{CSF}+3 \%$ of $\mathrm{CMMLV}$; $\mathrm{A} 5: \mathrm{CSF}+5 \%$ of $\mathrm{CMMLV} ; \mathrm{V} 2: \mathrm{CSF}+2 \%$ cafeteria wastes microencapsulated liquid vermicompost (CWMLV); V3: CSF+3\% CWMLV; V5: CSF+5\% CWMLV; CNE:CSF + microencapsulated distilled water, and CN: CSF alone. Initial and average weight gain did not depict statistically significant differences among treatments, but there were significant differences in the specific growth rate and survival. The use of liquid vermicompost resulted in a plausible option to enhance shrimp nutrition. Further studies must be done to test how much shrimps can grow in a longer period and whether this additive can be an option to prevent shrimp diseases.
\end{abstract}

Keywords: shrimp, liquid vermicompost, microencapsulation, growth, survival
Volume 8 Issue 6 - 2019

\author{
Arturo Polanco Torres, Gerardo Rodríguez \\ Quiroz \\ Aquaculture Laboratory, Instituto Politécnico Nacional, Mexico
}

Correspondence: Gerardo Rodríguez Quiroz, Aquaculture Laboratory, Blvd Juan de Dios Bátiz Paredes 250, Col. San Joachin, Guasave, Sinaloa, Mexico, Tel +52 6878729625 , Email grquiroz@ipn.mx

Received: October 23, 2019 | Published: November 27, 2019

\section{Introduction}

World fishing to produce fish flour has reached the maximum sustainable yield with high consequences in the price and the nutritional level of products. But, one of their major challenges is to reduce food production costs. ${ }^{1}$ Until now, the aquaculture food industry depends only on fish flour consumption, which constitutes the highest value ingredient of shrimp food due to its protein quality, essential amino acids, and polyunsaturated fatty acids content. ${ }^{2}$ Mexico demands balanced aquaculture food for trout, tilapia, carp, catfish, and shrimp cultures.

Some organic acids, worms, and other high protein substances, containing most of the essential amino acids, and a predominance of polyunsaturated fatty acids with significant amounts of linoleic and linolenic acid have been proven to bean excellent food additive for fish, poultry, pigs, or domestic animals, ${ }^{3,4}$ as well as to measure growth and as antimicrobial agents in aquaculture, especially for shrimp culture. ${ }^{5}$ It has been shown that they have a better performance in growth and survival than control treatments in low quantities, ${ }^{6,7}$ making them a potential food additive for shrimps. ${ }^{5}$

Much research has been focused on finding alternatives to substitute fish protein in food for aquatic species, like fishes ${ }^{8}$ and crustaceans. ${ }^{9}$ Several studies have been done to substitute partially or totally fish protein with natural and lower cost ingredients. ${ }^{10}$ The worm Eisenia foetida has been used as a protein source in pets and little ruminants food, because of its high protein content, between 50 a $67 \%$, and has been included in experimental aquatic feed, ${ }^{8}$ but its use is less known in shrimp culture, ${ }^{11}$ the use of vermicompost sub products has not been tested as food complement.

On the other hand, microparticulated and microencapsulated diets as partial substitute of animal food have yielded survival and development rates similar to those obtained with live food but with lower growth. ${ }^{11,12}$ Thus, we can consider that the use of liquid vermicompost in microcapsules as an additive in shrimp feed could have some influence in the crustacean's behavior.

The purpose of this research was to add microcapsules with liquid vermicompost as a natural immune enhancer to stimulate disease resistance in shrimp, but they were also used as a complement in shrimp food to observe shrimp survival and growth. Different doses of these microcapsules from two different vermicompost wastes were proven as important sources of protein.

\section{Materials and methods}

The experiment was done in the laboratory with controlled parameters of temperature, salinity, and oxygen. Worms were added to two different organic waste beds: one with cow manure and the other with cow manure and cafeteria wastes. The vermicompost beds were moisturized during three months and, at the end of the third month, the vermicompost liquid from the two beds was collected. Three liters of each liquid were filtered to separate all suspended solids and to be microencapsulated in a Spray Dryer ADL311S (Yamato Scientific America, Japan) for three hours.

Ground Purina ${ }^{1}{ }^{1}$ commercial shrimp food (CSF) with $40 \%$ protein was added to each of the eight treatments, as follows: $\mathrm{A} 2$ : $\mathrm{CSF}+2 \%$ of microencapsulated vermicompost liquid from cow manure (CMMLV) + alginate + maltodextrin ${ }^{2}+$ fish oil; $\mathrm{A} 3: \mathrm{CSF}+3 \%$ of $\mathrm{CMMLV}+$

${ }^{1}$ Purina $0: 12.00 \%$ maximum humidity, $40.00 \%$ minimum protein, $7.70 \%$ minimum fat, $3.50 \%$ maximum crude fiber, $11.20 \%$ maximum ashes.

${ }^{2}$ Maltodextrin is a mixture of glucose polymers that appear as a result of starch hydrolysis. 
alginate + maltodextrin + fish oil; $\mathrm{A} 5: \mathrm{CSF}+5 \%$ of $\mathrm{CMMLV}+$ alginate + maltodextrin + fish oil; $\mathrm{V} 2: \mathrm{CSF}+2 \%$ microencapsulated vermicompost liquid from cafeteria wastes $(\mathrm{CWMLV})+$ alginate + maltodextrin + fish oil; V3: CSF+3\% CWMLV+ alginate + maltodextrin+ fish oil; V5: $\mathrm{CSF}+5 \% \mathrm{CWMLV}+$ alginate + maltodextrin + fish oil $\mathrm{CNE}: \mathrm{CSF}+$ microencapsulated distilled water + alginate + maltodextrin + fish oil; and $\mathrm{CN}$ : CSF alone.

Ten shrimps were placed in 3-L fish bowls with three replicates for each treatment. Shrimp juveniles had an average weight of $0.585 \pm 0.101248 \mathrm{~g}$ at the beginning of the experiment. The experiment lasted 15days and the water of the fish bowls was changed every 2 days to prevent nitrification by shrimp excreta and food surpluses.

We measured survival, specific growth rate (SGR), and weight gain at the end of the experiment. All data were analyzed with oneway ANOVA and Tukey test.

\section{Results}

Salinity, $\mathrm{pH}$, and oxygen were the same for all treatments during the experiment. All treatments were fed at the same hour and the water was cleaned on the next day. Initial average weight was not statistically significant different among treatments. There were no significant differences among treatments, but A2 had the highest weight gain with $0.0978 \mathrm{~g}$ (Figure1) followed by $\mathrm{CN}$ with $0.963 \mathrm{~g}$, which had no liquid vermicompost.

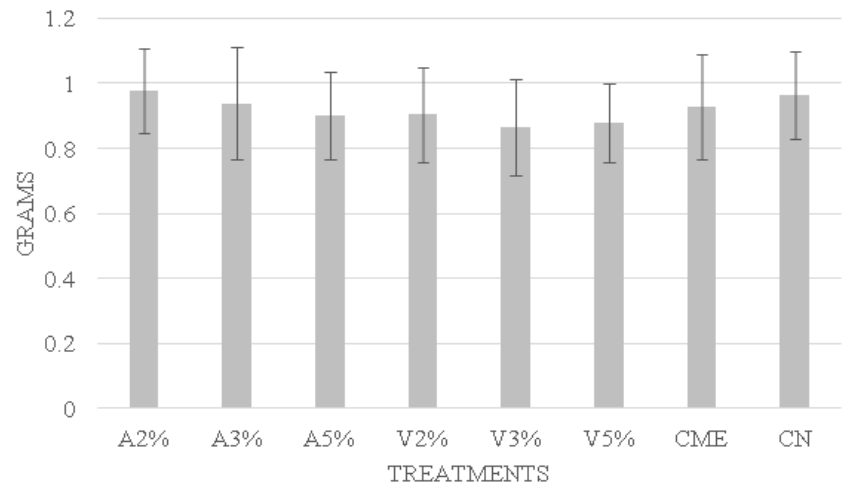

Figure I Weight after I5 days of experiment.

SGRdepicted significant differences among treatments. Treatment A2 had the best performance with $0.368 \mathrm{~g}(\mathrm{p}=0.000042)$, followed by CME with $0.365 \mathrm{~g}(\mathrm{p}=0.000051)$. The treatment with the lowest value was V5 with $0.277 \mathrm{~g}(\mathrm{p}=0.314123$; Figure 2$)$. Since the first measure, this treatment had this behavior throughout the whole experiment.

There were statistical differences among treatments in survival. Treatments A2 and $\mathrm{CN}$ presented $100 \%$ of survival. The lowest survival was for A3 with $70 \%$ (Figure 3 ).

\section{Discussion and conclusion}

Recent studies on the effect of organic acid supplementations in aquaculture diets have focused on their used as growth promoters and bacterial prophylaxis. ${ }^{13}$

In our study, low amounts of liquid animal vermicompost as a supplement in shrimp food yield eda good response in shrimp growth and survival. ${ }^{13,14}$ Febrianti et al. ${ }^{15}$ reported that dietary symbiotic microcapsules could improve the absorption of nutrients and growth performance, this statement can be applied to the vermicompost that can be absorbed by bacterial metabolism in the gut. ${ }^{5,16}$ Yao et al. ${ }^{17}$ mention that crude protein can be improved significantly with these diets of additives supplementation; some studies have reported that organic acids, such as liquid vermicompost, can improve growth, feed utilization, gut health, and disease resistance in aquatic animals, and will benefit shrimp farming in water reservoirs and closed recirculating water culture systems. ${ }^{18}$

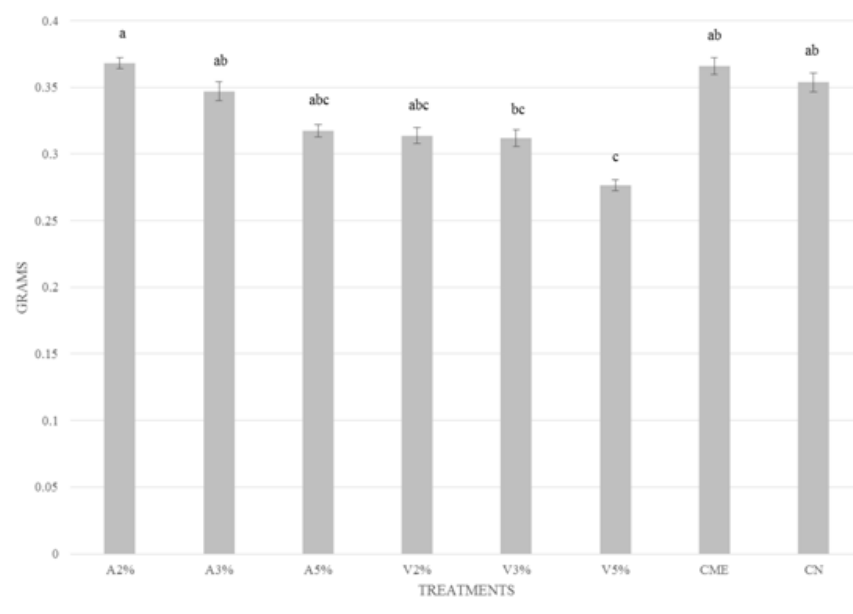

Figure 2 Weight gained according to treatment during the 15 days of the experiment.

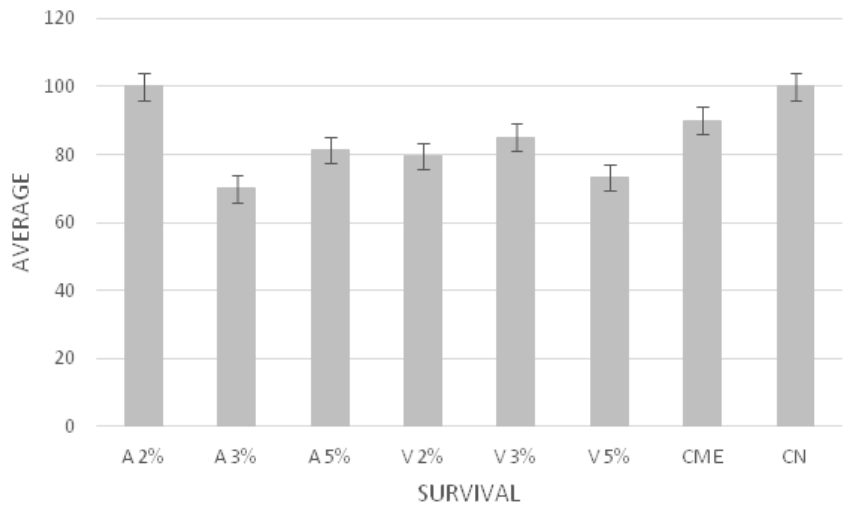

Figure 3 Survival throughout the experiment.

The use of liquid vermicompost can be a possibility to enhance shrimp nutrition. Further studies must be done to test how much shrimps can grow in a longer period and whether the liquid vermicompost supplementation can be an option to prevent shrimp diseases.

\section{Acknowledgment and funding}

To the Instituto Politécnico Nacional for the administrative and financial support to our research (Grant SIP20170522).

\section{Conflicts of interest}

The authors declare that there are no conflicts of interest. 


\section{References}

1. FAO Stat - Food and Agriculture Organization of the United Nations Statistics Division. Food balance. 2015.

2. Peters D RR, Rodríguez de HS, Hernández JL, et al. Determinación del nivel óptimo de Sustitución de la harina de pescado por harina de hidrolizado de plumas en el alimento para tilapia roja, Oreochromis sp. CIENCIA. 2004;12(1):13-24.

3. Qiu X, Buentello A, Shannon R, et al. Evaluation of three non-genetically modified soybean cultivars as ingredients and a yeast-based additive as a supplement in practical diets for Pacific white shrimp Litopenaeus vannamei. Aquaculture Nutrition. 2018;24(1):173-183.

4. Chaudhuri PS. Vermiculture and vermicomposting as biotechnology for conversion of organic wastes into animal protein and organic fertilizer. Asian Journal of Microbiology, Biotechnology and Environmental Sciences. 2005;7(3):359-370.

5. Duan Y, Wang Y, Zhang J, et al. Dietary effects of succinic acid on the growth, digestive enzymes, immune response and resistance to ammonia stress of Litopenaeus vannamei. Fish and Shellfish Immunology. 2018;78:10-17.

6. Rodrigues MS, Bolívar N, Legarda EC, et al. Mannoprotein dietary supplementation for Pacific white shrimp raised in biofloc systems. Aquaculture. 2018;488:90-95.

7. Jantarathin S, Borompichaichartkul C, Sanguandeekul R. Microencapsulation of probiotic and prebiotic in alginate-chitosan capsules and its effect on viability under heat process in shrimp feeding. Materials Today: Proceedings. 2017;4(5):6166-6172.

8. Montoya-Mejía M, Hernández-Llamas A, García-Ulloa M, et al. Apparent digestibility coefficient of chickpea, maize, high-quality protein maize, and beans diets in juvenile and adult Nile tilapia (Oreochromis niloticus). Revista Brasileira de Zootecnia. 2016;45(8):427-432.

9. Bachère E. Shrimp immunity and disease control. Aquaculture. 2000;191:3-11.

10. Sklan D, Prag T, Lupatsch I. Apparent digestibility coefficients of feed ingredients and their prediction in diets for tilapia Oreochromis niloticus x Oreochromis aureus (Teleostei, Cichlidae). Aquaculture Research. 2004;35:358-364.
11. Gallardo P, Martínez G, Palomino G, et al. Replacement of Artemia franciscana Nauplii by Microencapsulated Diets: Effect on Development, Digestive Enzymes, and Body Composition of White Shrimp, Litopenaeus vannamei, Larvae. Journal of the World Aquaculture Society. 2013;44(2):187-197.

12. Sarvi B, Matinfar A, Mahmoudzadeh H, et al. Replacing rotifer with a microparticle diet from first feeding in yellowfin seabram, Acanthopagrus latus (Houttuyn), larvae. Aquaculture Research. 2010;41:1614-1621.

13. Romano N, Koh CB, Ng WK. Dietary microencapsulated organic acids blend enhances growth, phosphorus utilization, immune response, hepatopancreatic integrity and resistance against Vibrio harveyi in white shrimp, Litopenaeus vannamei. Aquaculture. 2015;435:228-236.

14. Ng WK, Koh CB, Teoh CY, et al. Farm-raised tiger shrimp, Penaeus monodon, fed commercial feeds with added organic acids showed enhanced nutrient utilization, immune response and resistance to Vibrio harveyi challenge. Aquaculture. 2015;449:69-77.

15. Febrianti D, Munti Y, Widanarni. Dietary Synbiotic Microcapsule Influence the Immune Responses, Growth Performance and Microbial Populations to White Spot Syndrome Virus in Pacific White Shrimp (Litopenaeus vannamei). Journal of Fisheries and Aquatic Science. 2016;11(1):28-42.

16. Li E, Xu C, Wang X, et al. Gut Microbiota and its Modulation for Healthy Farming of Pacific White Shrimp Litopenaeus vannamei. Reviews in fisheries science and aquaculture. 2018;26(3):381-399.

17. Yao W, Li X, Kabir Chowdhury MA, et al. Dietary protease, carbohydrase and micro-encapsulated organic acid salts individually or in combination improved growth, feed utilization and intestinal histology of Pacific white shrimp. Aquaculture. 2019 503:88-95.

18. Ng WK, Koh CB YC. The utilization and mode of action of organic acids in the feeds of cultured aquatic animals. Reviews in Aquaculture. 2017;9:342-368. 